\title{
Regenerative medicine: the blurred boundaries between life sciences and biotechnology towards a new inductive medicine of the third millennium
}

\author{
Mario Marazzi, ${ }^{1}$ Federica Mingotto, ${ }^{2}$ Marta Cecilia Tosca, ${ }^{1}$ Barbara Antonioli, ${ }^{1}$ Marta Galuzzi, ${ }^{1}$ Maria Luisa Torre, ${ }^{3}$ \\ Caterina Tartaglione, ${ }^{1}$ Demetrio Manenti, ${ }^{4}$ Alessandro Scalise ${ }^{5}$
}

${ }^{1}$ Regional Centre for in vitro Human Epidermis Cultivation and Bank for Cryopreservation of Tissues, Tissue Therapy Unit, Niguarda Ca' Granda Hospital, Milan, Milan; ${ }^{2}$ Molmed S.p.a, Milan; ${ }^{3}$ Department of Drug Sciences, University of Pavia, Pavia, Italy; ${ }^{4}$ Sildeha, Paradiso, Switzerland; ${ }^{5}$ Department of Plastic and Reconstructive Surgery, University Hospital of Ancona, Ancona, Italy

\section{INTRODUZIONE}

Per avere donato il fuoco all'uomo, Prometeo venne incatenato sul monte Caucaso. Ogni giorno un'aquila gli squarciava il petto e gli divorava il fegato che ogni notte ricresceva. Nell'immaginazione del genere umano, l'idea della rigenerazione nella cura medica inizia come ci racconta nella sua opera Prometeo incatenato. Probabilmente, osservando la sopravvivenza di alcuni dei feriti in battaglia, nell'antica Grecia si erano resi conto della capacità di rigenerazione del fegato. Anche il filosofo Aristotele, nel IV secolo a.C. Aveva osservato che gli occhi perforati dei pulcini guarivano, cosi come le code della salamandre, se recise, ricrescevano.

Che gli organismi viventi fossero capaci di autorigenerarsi, quindi, lo si sapeva dall' antichità, ma che tale capacità fosse necessaria per la vita stessa è conquista della biologia, che di ciò si è occupata fin dagli inizi del XVIII secolo, quando il metodo sperimentale divenne lo strumento indispensabile per raggiungere la conoscenza. Alcuni naturalisti del periodo come R.A Ferchault de Réaumur, studiarono la rigenerazione degli arti nei cro-

Correspondence: Mario Marazzi, Regional Centre for in vitro Human Epidermis Cultivation and Bank for Cryopreservation of Tissues, Tissue Therapy Unit, Niguarda Ca' Granda Hospital, Milan, Milan, Italy.

E-mail: mario.marazzi@ospedaleniguarda.it

Key words: Regenerative medicine; Inductive medicine; Life sciences; Biotechnology.

Received for publication: 9 October 2017.

Accepted for publication: 12 October 2017.

This work is licensed under a Creative Commons Attribution NonCommercial 4.0 License (CC BY-NC 4.0).

(C) Copyright M. Marazzi et al., 2017

Licensee PAGEPress, Italy

Italian Journal of Wound Care 2017; 1(1):34-51

doi:10.4081/ijwc.2017.17 stacei, altri come Abraham Trembley scoprirono la Hydra e studiarono la sua capacità di rigenerazione. Così commentava l'Accademia di Scienze di Parigi nel 1741: $L a$ storia della Fenice che rinasce dalle proprie ceneri, per quanto favolosa, non offre nulla di più meraviglioso del polipo del signor Trembley: da ciascuna porzione di quell'animale tagliato in quante parti si voglia rinascono altrettanti esemplari simili all'originale.

Ad oggi, la maggior parte dei trattamenti terapeutici sono di tipo sintomatico, ovvero volti a rallentare la progressione della patologia; di fatto, in entrambi i casi si assiste alla cronicizzazione della malattia. Il risultato è un sistema sanitario gravato da costosi trattamenti, con poche soluzioni concrete per contenere l'aumento dei costi legato all'invecchiamento della popolazione ed all'aumento del numero dei malati. Nei soli Stati Uniti la spesa per le cure sanitarie ammontava a 2,2 trilioni di dollari nel 2006 (16\% del Gross Domestic Product - GDP) ed è gravitata fino a 3,6 trilioni nel 2011, un aumento di 1,6 volte. Le statistiche stimano che per il 2016 la spesa sanitaria potrebbe superare i 4,5 trilioni di dollari e che, per il 2040, in cui si calcola che la popolazione anziana sarà raddoppiata, la spesa sanitaria potrebbe arrivare a rappresentare più del $25 \%$ del GDP.

Il modo migliore per tutelare l'economia del nostro sistema sanitario e, più in generale, delle spese sanitarie globali, è quello di sviluppare trattamenti efficaci per le malattie più onerose, quali diabete, patologie neurodegenerative, patologie cardiovascolari, patologie dell'apparato muscolo scheletrico e cutaneo. I potenziali benefici della Medicina Rigenerativa sono enormi, considerato che ogni anno, solamente negli Stati Uniti, 250.000 pazienti sono operati per patologie valvolari cardiache, 900.000 persone muoiono per cardiopatie, compreso l'infarto miocardio, 16 milioni di diabetici risultano in terapia sostitutiva, 5,5 milioni di persone soffrono di patologie neurodegenerative e altrettanti pazienti necessitano innesti di tessuto muscolo scheletrico e cutaneo.

Quando possibile, questi nuovi approcci terapeutici dovrebbero limitarsi a stimolare e sostenere le capacità proprie di guarigione dell'organismo umano, includendo, senza limitazioni, l'uso di molecole solubili, terapie ge- 
niche, terapie basate sull'uso di cellule staminali e/o progenitrici, ingegneria tissutale e riprogrammazione cellulare e/o tissutale.

Il benessere economico, i vantaggi della medicina tradizionale e il progressivo miglioramento degli standard d'igiene hanno portato ad un aumento consistente della durata media della vita, tendenza demografica destinata inevitabilmente ad aumentare nei prossimi anni. Stime pubblicate dal Directorate General for Health \& Consumers della Commissione Europea prevedono che entro il 2050 più del $25 \%$ della popolazione avrà dai 60 ai 65 anni, e il $20 \%$ della popolazione avrà più di 80 anni.

La società del futuro, dunque, dovrà affrontare le problematiche che scaturiranno dal consistente aumento degli anziani.

La fusione tra biomedicina e biotecnologie è un processo che si è andato progressivamente strutturando in modo sistematico a partire dalla seconda metà del Novecento nel tentativo di spiegare unitariamente la complessa realtà del mondo vivente, con la finalità di manipolare e trasformare positivamente l'esistenza degli individui così da arrivare all'ambizioso obiettivo di curare nel modo più efficace possibile le loro condizioni patologiche.

Le biotecnologie detengono poteri nuovi e formidabili che non soltanto ricostruiscono la vita, ma la costruiscono dal nulla.

Le biotecnologie sono inoltre in grado di incidere profondamente anche in ambito medico con ricadute positive sia sul versante diagnostico sia su quello terapeutico.

Questi rapidi cambiamenti tecnologici nel settore sanitario hanno una radice storica plurisecolare che è opportuno puntualizzare per comprendere la realtà presente e cogliere le prospettive future.

Nel Settecento e nel primo Ottocento il processo di trasformazione metodologica che nel secolo precedente aveva investito la fisica, coinvolge anche la chimica e la biologia. Durante l'Ottocento giunge a maturazione anche il lungo percorso, iniziato nel Cinquecento, che aspira a portare progressivamente la medicina da arte empirica a scienza esatta.

Nel Settecento l'anatomico italiano Giovanni Battista Morgagni (1682-1771) attraverso le osservazioni De sedbusis et causis morborum per anatomen indagatis $(1761)^{1}$ : mostra che i sintomi di malattia sono espressione di un'alterazione patologica degli organi interni, egli stabilisce l'esistenza di un rapporto di causa-effetto tra modificazione morfologica e manifestazione morbosa identico a quello osservabile sperimentalmente nei fenomeni delle scienze fisiche e chimiche. Tale approccio metodologico si rivela corretto e la correlazione tra la causa e la sede del processo patologico viene precisata in modo sempre più stringente: dagli organi ai tessuti, come dimostra nel Traité des membranes (1799) ${ }^{2}$ MarieFrançois-Xavier Bichat (1771-1802, dai tessuti alla cel- lula, come sostiene nel suo Cellularpathologie $(1855)^{3}$ Rudolf Virchow (1821-1902).

Cambia anche il modo di osservare il malato e di rapportarsi con esso. Fra i due momenti ippocratici dell'atto medico, l'anamnesi (la storia del passato remoto e prossimo del malato ascoltata dal medico) e la prognosi (la storia del futuro dell'ammalato detta dal medico, in risposta alle attese e alle speranze di guarigione e di vita del paziente), s'inserisce la diagnosi, centrata sul presente e mirante a definire con precisione la malattia.

Per realizzare questo passaggio il medico deve produrre una casistica di storie cliniche per poter ricavare da essa una tipologia patologica con cui confrontare la malattia del proprio paziente, realizzando una classificazione tipologica delle varie forme morbose (nosologia) che utilizza lo stesso metodo usato alcuni decenni prima da Carlo Linneo (Carl von Linné, 1707-1778) .

Oltre che predire l'evoluzione futura della malattia, egli deve comparare i quadri clinici. Oltre che ascoltare i sintomi riferiti come impressioni soggettive dal paziente, egli deve ricercare i segni quali espressioni oggettive di un'alterazione patologica degli organi, dei tessuti, delle cellule del corpo malato.

La nascita della clinica è strettamente connessa all'esigenza di rendere la malattia il più possibile oggettiva, superando l'approccio della visione soggettiva che in precedenza aveva sempre guidato il medico e il suo occhio clinico. Al paradigma antropologico, che aveva informato la medicina del passato, si va sostituendo il paradigma tecnologico, destinato ad assumere un ruolo crescente nella medicina futura.

Pierre-Charles-Alexandre Louis (1787-1872), effettuando Recherches sur les effets de la saignée, ${ }^{4}$ una pratica medica di comune ed esteso uso, utilizza un criterio matematico di analisi dei dati, il metodo statistico, introducendo così anche in medicina un criterio di valutazione obiettivo per verificare l'efficacia di tale procedura terapeutica. L'impiego del metodo numerico in ambito medico opera una vera e propria rivoluzione e, a partire dalla seconda metà dell'Ottocento, lo sviluppo della statistica medica innalza la medicina al rango di scienza.

La malattia non è più dunque un'astrazione, un malessere soggettivo comunicato dal malato al medico, ma una realtà tangibile, misurabile e quantificabile in modo oggettivo.

L'identificazione delle modalità attraverso cui le cellule sono in grado di comunicare tra loro sia in fase di sviluppo sia successivamente apre nuove importanti prospettive in ambito biologico e medico. Nel 1901 William Maddock Bayliss (1860-1924) ed Ernest Henry Starling (1866-1927) forniscono la prima dimostrazione dell'esistenza di effettori chimici endogeni in grado di regolare risposte fisiologiche organizzate. È la premessa che porta alla successiva scoperta degli ormoni, intesi come 
messaggeri chimici trasportati nel sangue dall'organo di produzione (secretore) all'organo di azione (effettore). Sono le basi biologiche della nascente endocrinologia, destinata a spiegare fisiologia e patologia delle ghiandole a secrezione interna. Tra il 1948 e il 1952 l'italiana Rita Levi-Montalcini (1909-2012) ipotizza e dimostra l'esistenza in alcuni tumori di un fattore biochimico in grado di stimolare la crescita dei nervi. La scoperta del Nerve growth factor porta alla comprensione delle basi biochimiche della comunicazione tra cellule in fase di sviluppo (e quindi alla spiegazione dei complessi meccanismi di controllo del differenziamento e della morfogenesi del sistema nervoso) e apre la strada all'identificazione, nei decenni successivi, di numerosi altri fattori di crescita, proteine in grado di stimolare la proliferazione e il differenziamento cellulare, che assumeranno poi, soprattutto in questi ultimi vent'anni, un ruolo importante nel trattamento di diverse malattie del sangue e di alcuni tumori.

Nei primi decenni del Novecento la semplice osservazione microscopica della cellula viene affiancata e sostituita da tecniche di analisi più raffinate, a livello molecolare e macromolecolare. La biologia cellulare si trasforma in biologia molecolare, oggetto della biologia molecolare è lo studio del rapporto tra struttura e funzione delle macromolecole biologiche (proteine e acidi nucleici).

Nanotecnologie e farmaci molecolari costituiscono oggi l'ultima frontiera della tecnologia farmacoterapica. Le proprietà che la materia assume a dimensioni nanometriche (cioè con una scala dimensionale inferiore al micrometro, vale a dire tra 1 e 100 nanometri) rendono complesse la costruzione e la sperimentazione di nanodispositivi, che però possono fornire prestazioni straordinarie. L'applicazione medica di queste particolari tecnologie ha dato vita alla nanomedicina: un settore innovativo destinato ad avere un impatto rivoluzionario in ambito diagnostico e terapeutico. In particolare di quest'ultimo settore si occupa la nanofarmacologia, che utilizza nanoparticelle (vettori) per realizzare nanofarmaci dotati di caratteristiche farmacocinetiche $\mathrm{e}$ di potenzialità farmacoterapeutiche impossibili per farmaci di grandezza superiore al micrometro.

Questi nanofarmaci sono in grado di agire su bersagli molecolari in modo esclusivo e selettivo (come avviene, per es., nella farmacologia del ribonucleic acid, RNA) e di esplicare proprietà farmacologiche peculiari: come la possibilità di inglobare un'elevata quantità di farmaco, che è possibile veicolare direttamente sul tessuto malato e nelle cellule patologiche (per es., nei tumori), e di consentire, grazie alla maggiore solubilità, una più prolungata esposizione al farmaco; oppure la possibilità di rilasciare contemporaneamente più farmaci, contenuti nella stessa nanoparticella, grazie a farmacocinetiche differenti e appropriate; o ancora la possibilità, utilizzando questi nanovettori, di far attraversare senza difficoltà ai farmaci la barriera emato-encefalica, la membrana cellulare e il citoplasma, in modo da raggiungere facilmente i target terapeutici.

Le nanotecnologie rappresentano dunque, in ambito medico e farmacologico, la via privilegiata per dare corpo a quella medicina personalizzata alla quale aspira la sanità del nuovo millennio e per realizzare quella farmacologia individualizzata a cui tende l'approccio terapeutico del futuro.

\section{DAI TRAPIANTI ALLA MEDICINA RIGENERATIVA}

Il mito del trapianto di organo ha affascinato l'uomo sin dall'antichità. In ambito sanitario l'idea che nel corpo dell'uomo, concepito come una macromacchina costituita da un insieme di micromacchine (organi, tessuti, cellule) armonicamente funzionanti, fosse possibile sostituire le parti inefficienti con nuovi pezzi, trova il suo fondamento teorico nella medicina meccanica del Seicento.

I primi resoconti sui trapianti di tessuti, di ossa e di pelle risalgono però al Quattrocento. Durante il Rinascimento, il medico bolognese Gaspare Tagliacozzi (15451599) sviluppò un metodo per la ricostruzione del naso utilizzando gli stessi tessuti cutanei del paziente, affermando già allora che la specificità dell'individuo impediva fondamentalmente di eseguire quest'intervento su un'altra persona e anticipando in tal modo uno dei maggiori problemi della medicina dei trapianti: il rigetto.

Nel 1801 Giuseppe Baronio riferisce di innesti cutanei riusciti tra specie animali differenti, ma solo nella seconda metà dell'Ottocento le diverse possibilità di successo di trapianti tra organismi vengono studiate sperimentalmente in modo sistematico da Paul Bert (1833-1886), allievo di Claude Bernard (1813-1878), che nel 1863 nel libro De la greffe animale dimostra che gli autotrapianti (isotrapianti) attecchiscono sempre, mentre gli omotrapianti (allotrapianti) e gli eterotrapianti (xenotrapianti) hanno un indice di successo inversamente proporzionale alla complessità degli organismi sui quali vengono sperimentati, risultando di fatto impossibili nei mammiferi.

A partire dal 1944 Peter Medawar (1915-1987) inizia a studiare sistematicamente la fenomenologia del rigetto e nel 1953 è in grado di annunciare, insieme a Rupert Everett Billingham (1921-2002) e Leslie Brent (n. 1925), che il rigetto di un trapianto è dovuto a una reazione immunitaria e che è possibile indurre una tolleranza immunitaria specifica al trapianto. Le basi genetiche dell'istocompatibilità nell'uomo, scoperte dall'immunologo Jean Dausset (1916-2009) verso la fine degli anni Cinquanta, consentono di realizzare, nella prima metà degli anni Sessanta, la tipizzazione immunogenetica (il confronto tra $\mathrm{i}$ profili genetici rappresentati a livello degli antigeni di istocompatibilità), che diventa la tecnica di routine per 
stabilire il grado di compatibilità tra donatore e ricevente in vista del trapianto.

L'era dei trapianti d'organo inizia però realmente solo a partire dai primi anni Sessanta, grazie all'immunosoppressione ottenuta dall'uso dei primi farmaci antirigetto, come l'aziatioprina e la 6-mercaptopurina, associati a steroidi. Un altro portentoso farmaco antirigetto, la ciclosporina, scoperta nel 1972 e introdotta nella medicina dei trapianti nel 1983, permette la messa a punto di protocolli terapeutici sempre più efficaci, consentendo con successo il trapianto di molti altri organi: polmone nel 1977, visceri addominali multipli nel 1989, intestino nel 1992, mano nel 1998, viso nel 2010.

Quella dei trapianti è una delle diverse tecnopratiche terapeutiche realizzate grazie alla rivoluzione tecnologica che, a partire dal secondo dopoguerra, ha interessato massivamente anche la chirurgia, favorendo l'utilizzo sempre più diffuso dell'endoscopia operativa, del microscopio operatorio, della chirurgia mini-invasiva, della radiologia interventistica e della chirurgia robotica.

La tecnologia sanitaria interviene anche nello spazio fisico in cui il chirurgo lavora, trasformando la sala operatoria in teatro chirurgico, un ambiente in cui, oltre al tradizionale letto operatorio, sono poste macchine altamente tecnologiche in grado di coadiuvare e integrare l'opera del chirurgo: apparati diagnostici radiologici computerizzati (TAC), apparecchiature ottiche ed elettroniche (monitor visivi amplificanti il campo operatorio), macchine meccaniche di precisione (robot operatori), strumenti informatici in grado di simulare le procedure operatorie da eseguire (intervento virtuale).

Una biotecnoterapia alternativa alla medicina sostitutiva dei trapianti è quella attuata dalla medicina rigenerativa, con l'impiego delle cellule staminali, che rappresenta oggi la frontiera più avanzata e promettente in ambito sanitario. Essa costituisce una nuova filosofia di approccio alla malattia: utilizzare la rigenerazione biologica realizzata dal corpo del paziente del tessuto o dell'organo malato anziché la sua sostituzione con un trapianto.

La prospettiva di utilizzare le cellule staminali presenti, con diversi assetti fisiologici, sia nell'embrione, sia nel feto, sia nell'organismo adulto, a fini terapeutici rigenerativi e riparativi per gravi condizioni traumatiche o malattie degenerative (come il morbo di Parkinson, l'infarto cardiaco o il diabete), si fa strada negli ultimi anni del Novecento.

Al di là dei problemi etici legati all'uso di cellule staminali embrionali (superabile ricorrendo a cellule adulte fatte regredire alla fase di totipotenza) e alla soluzione di numerose questioni tecniche (dalla transdifferenziazione, cioè la capacità d'indirizzare in coltura le staminali verso il fenotipo citologico che si vuole ottenere, al controllo del potenziale tumorigeno), questa tecnica permetterebbe una terapia biologica mirata efficiente ed efficace di molte condizioni patologiche. In particolare, si potrebbe superare lo stallo oncologico in cui si trova oggi la terapia delle malattie neoplastiche e affrontare con maggiore determinazione l'impotenza comportamentale di fronte alle malattie neurodegenerative.

Il compito delle scienze della vita appare perciò fondamentale nel definire i limiti culturali entro i quali conoscenza teorica e pratica quotidiana devono tentare di ricomporre l'unità esistenziale dell'uomo.

In questo ambito la tecnomedicina manifesta una tendenza, destinata a rafforzarsi sempre più, per cui il malato confida non tanto nel medico curante, quanto nelle cure, intese queste ultime come esami diagnostici del danno biologico subito e come interventi terapeutici (farmacologici, chirurgici, riabilitativi) riparatori di quel danno. La grande importanza attribuita alla diagnosi precoce dalla medicina preventiva, fondata sulla percezione altrettanto precoce dei sintomi, e ancor di più oggi dalla medicina predittiva, fondata sulla convinzione di poter conoscere, in relazione alla conformazione genetica di un soggetto, la sua suscettibilità individuale alle malattie in modo da operare perché non si manifestino, o per procrastinarne l'insorgenza, crea allarme e un clima eccessivo di attese.

Molte di queste attese non vengono risolte da una tecnologia medica di pur alto livello. Esse potrebbero invece essere esaudite all'interno di un rapporto relazionale interumano tra medico e paziente, che invece si sta impoverendo e perdendo, mettendo per ciò stesso sovente in crisi e in discussione l'accettazione e l'impiego da parte del malato dell'attuale enorme potenziale terapeutico della biomedicina.

\section{L'INGEGNERIA DEI TESSUTI E QUADRO NORMATIVO}

\section{Premessa}

L'enorme progresso delle conoscenze nel campo della biologia cellulare e delle biotecnologie ha consentito, negli ultimi 20 anni, lo sviluppo di tecnologie mirate alla coltivazione ed alla ricostruzione in vitro di tessuti ed ha messo a disposizione della comunità medica nuove possibilità terapeutiche attraverso l'impiego di prodotti che utilizzano cellule ottenute e/o tessuti ex vivo dallo stesso paziente o da donatore.

Queste tecnologie contribuiscono a definire una nuova branca delle scienze biomediche: l'ingegneria dei tessuti.

\section{Ingegneria tissutale}

L'ingegneria tissutale è stata definita nel 1998 come una tecnica interdisciplinare che applica i principi e i metodi dell'ingegneria e delle scienze biologiche con l'obiettivo di comprendere le relazioni fondamentali tra struttura e funzione nei tessuti sani e malati dei mammiferi e di svi- 
luppare sostituti biologici in grado di ripristinare, mantenere o migliorarne le funzioni $i^{5}$ come Cute, Osso, Cartilagine, Vasi Sanguigni, Vescica, ecc. La rigenerazione dei tessuti in vitro mediante l'Ingegneria dei Tessuti è volta alla creazione in vitro di tessuti qualitativamente e quantitativamente idonei a sopperire alle necessità cliniche, superando in tal modo i limiti dei biomateriali eubiotici (derivanti da esseri viventi) e di quelli xenobiotici (di origine sintetica).

L'ingegneria tissutale rappresenta un settore d'importante e di crescente interesse medico ed industriale ed è caratterizzato da una grande interdisciplinarità che prevede la collaborazione di diverse figure professionali. Gli ambiti interessati sono: le scienze di base, la scienza dei biomateriali, le biotecnologie, la bioingegneria, la medicina rigenerativa e la biologia molecolare ${ }^{6}$ Tra le diverse discipline che formano le competenze dell'ingegneria tissutale, un'importanza rilevante assume la biologia cellulare; risulta, infatti, sempre più necessario studiare e comprendere nei dettagli i meccanismi che regolano la crescita, la proliferazione e la differenziazione delle cellule modalità attraverso le quali i componenti della matrice extracellulare interagiscono con le funzioni cellulari. Anche l'immunologia risulta rilevante per mettere a punto trapianti compatibili con l'organismo ricevente. La tecnologia s'interessa anche di mettere a punto sistemi per la coltivazione in vitro su larga scala di cellule, al fine di disporre di numerose cellule che possono essere successivamente seminate su un scaffold poroso di forma e architettura definita.

La coltivazione in vitro si pone, quindi, l'obiettivo di risolvere la carenza di tessuti e organi per il trapianto e, al tempo stesso, il problema del rigetto, dal momento che le cellule provengono dallo stesso paziente che riceverà il tessuto rigenerato. Ciò incide notevolmente sulla qualità della vita, poiché il processo rigenerativo iniziato in vitro è continuato in maniera più efficiente ed efficace anche in vivo. ${ }^{6-8}$

La riparazione cutanea e l'ortopedia sono stati i primi campi di applicazione delle tecniche del Tissue Engineering, e sono tuttora il settore in cui i prodotti dell'ingegneria tissutale sono più numerosi e maggiormente diffusi in ambito clinico.

Lo studio dei materiali utilizzati nell'ingegneria tissutale rappresenta un ulteriore importante settore di ricerca. I materiali naturali hanno il vantaggio di presentare particolari sequenze segnale che favoriscono l'adesione delle cellule mantenendone le funzioni. I materiali di sintesi, invece, hanno il pregio di essere riproducibili, essendo possibile la regolazione delle loro proprietà in fase di produzione ${ }^{6,9-11}$ Non mancano i problemi, primo tra tutti quello del rigetto conseguente all'interazione con l'organismo del ricevente. ${ }^{6}$

Lo scaffold fornisce un supporto 2D o 3D in grado di promuovere l'accrescimento e la diversificazione delle cellule e deve rispondere a caratteristiche meccaniche del tessuto che si vuole rigenerare. Il supporto artificiale, inoltre si dovrebbe preferibilmente riorganizzare ed essere riassorbito simultaneamente alla crescita cellulare e quindi gradualmente sostituito dai nuovi tessuti. Da questo punto di vista il materiale bioartificiale non può essere considerato come sostituto duraturo di un tessuto, ma come una struttura temporanea che ne promuove la rigenerazione.

Una sfida nel campo dell'ingegneria tissutale è quella di seminare e coltivare cellule su scaffold tridimensionali, nei quali la dimensione e l'interconnettività dei pori sono parametri importanti; ciò dovrebbe consentire una migliore migrazione delle cellule nei pori, l'apporto di elementi nutritivi e lo scambio di gas. Il successo della penetrazione cellulare all'interno dello scaffold è spesso determinato dall'efficienza della tecnica di semina e dalle condizioni di coltura, che svolgono un ruolo cruciale nella adesione e distribuzione cellulare sullo scaffold.

L'ingegneria tissutale è quindi un nuovo settore multidisciplinare delle biotecnologie che potrebbe rivoluzionare la medicina, consentendo di rigenerare gli organi e i tessuti malati invece di limitarsi semplicemente a ripararli.

La richiesta crescente di organi artificiali e supporti protesici (dovuta soprattutto all'aumento dell'età media degli individui ed alla loro maggiore disponibilità economica) insieme con i progressi raggiunti sia nelle metodologie di colture cellulari che nella ricerca di nuovi biomateriali, hanno alimentato l'interesse del settore, in questi ultimi anni, alla possibilità di riparare $i$ tessuti danneggiati favorendo la ricrescita delle stesse cellule, in modo da ripristinare il tessuto originale.

I tessuti e gli organi ingegnerizzati rappresentano un'alternativa ai donatori umani e la speranza per molti pazienti che aspettano di ricevere un trapianto.

Seguendo questo approccio l'Ingegneria dei Tessuti, negli ultimi 20 anni, ha raggiunto risultati incoraggianti nella ricreazione di alcuni tessuti come la cute, l'osso, le valvole cardiache e la cartilagine. Malgrado i notevoli successi ottenuti sembra però che l'Ingegneria dei Tessuti non sia cresciuta tanto velocemente quanto ci si aspettava, e l'ottenimento di tessuti 3D in vitro funzionali e spessi oltre i $2 \mathrm{~mm}$ appare ancora limitato.

L'Ingegneria dei Tessuti è basata sul seminare le cellule in uno scaffold polimerico biodegradabile o un gel, coltivare il costrutto scaffold-cellule in una Cell-Factory per varie settimane, e infine impiantare il tessuto risultante nell'organismo che deve riceverlo e in cui la maturazione del nuovo organo avrà luogo. ${ }^{11}$

Il trapianto di tessuti può essere di tre tipi. Si parla di trapianto autologo quando il materiale da impiantare proviene dal paziente stesso; in questo caso, si devono tenere in considerazione la limitata disponibilità di tessuto nelle 
regioni da cui si preleva il tessuto sano. Per allotrapianto, invece, s'intende il prelievo di tessuto utile da organismi della medesima specie. Infine, lo xenotrapianto è caratterizzato da tessuti provenienti da specie animali diverse. In questi ultimi due casi è necessario fronteggiare fenomeni acuti di rigetto attraverso terapie farmacologiche a base di immunosoppressori e altri farmaci che, oltre a costare tanto, devono essere effettuate per lunghi periodi di tempo causando, a lungo andare, assuefazione, intolleranza o anche comparsa di neoplasie. Inoltre, in tutti i trapianti è assolutamente indispensabile controllare che il tessuto o il materiale di provenienza umana o animale utilizzato per l'innesto non sia veicolo di gravi infezioni virali come HIV e epatite, ecc.

\section{Quadro normativo di riferimento}

Solo nell'anno 1999, il trapianto di tessuti e di cellule è stato regolamentato dalla Legge 91/99, che per la prima volta identificò quali Banche dei tessuti le strutture regionali di raccolta, manipolazione e distribuzione di tessuti umani. Nel 2003 sono state emanate le Linee Guida Nazionali deputate alla standardizzazione della trapiantologia, con particolare riguardo alla manipolazione tessutale e cellulare.

Poi, a partire dal 2004, la Commissione Europea ha emanato 3 Direttive (2004/23/CE, 2006/17/CE e 2006/86/CE), finalizzate alla standardizzazione delle procedure di biobanking di cellule e tessuti, attualmente recepite dalla legislazione italiana nel Decreto legislativo 06 novembre 2007, n. 191 e nel Decreto legislativo 25 gennaio 2010, n. 16.

È opportuno ricordare che i prodotti derivati dall'ingegneria dei tessuti sono definiti come farmaci, perché non sono assimilabili a trapianti in senso stretto (ad es. cuore, rene, cornea, osso, ecc), né possono essere definiti come tessuti artificiali (ad es. protesi valvolari), in quanto sono costituiti da cellule viventi isolate da tessuti, espanse in vitro, e associate a biomateriali con origine e caratteristiche diverse.

Per quanto attiene la manipolazione cellulare, sono state individuate 2 tipologie di lavorazione:

a) Manipolazione rilevante, con la quale caratteristiche biologiche, funzioni fisiologiche e proprietà strutturali delle cellule, pertinenti alle finalità di rigenerazione, riparazione o sostituzione, sono state alterate.

b) Manipolazione non rilevante, come prevista nell'allegato 1 del Regolamento CE 1394/2007, i prodotti ottenuti da procedure di manipolazione non rilevante rispondono alle normative precedentemente indicate per cellule e tessuti da trapianto.

I prodotti ottenuti dopo manipolazione rilevante, in base al Regolamento CE 1394/2007, sono identificati come medicinali per terapia avanzata e più precisamente: a) medicinali di terapia genica; b) medicinali di terapia cellulare somatica;

c) prodotti di ingegneria tessutale.

Altra caratteristica di questi prodotti è che le cellule siano impiegate nel ricevente per funzioni che non sono le stesse che avevano nel donatore (uso autologo), come per esempio la somministrazione di cellule staminali isolate dal midollo dell'osso e trasferite nel cuore del paziente (cioè in una sede in cui non sono normalmente presenti) dopo un infarto, con lo scopo di riparare il tessuto cardiaco danneggiato. L'uso autologo, anche se eseguito nello stesso paziente, ovvero il paziente è donatore e ricevente allo stesso tempo, è considerato terapia avanzata.

In tale quadro normativo, i medicinali per terapie avanzate sono sottoposti a specifiche normative di sicurezza biologica prima di poter essere commercializzati. In particolare devono ottenere un'autorizzazione all'immissione in commercio rilasciata dall'Agenzia Europea dei Medicinali (EMA), dopo una valutazione scientifica della domanda, vincolata all'esecuzione di rigorosi studi preclinici e clinici. L'autorizzazione alla commercializzazione è valida in tutta l'Unione europea, e non osta all'applicazione delle legislazioni nazionali in materia etica che vietano o limitano l'utilizzazione di tipi specifici di cellule umane o animali, nonché la vendita, la fornitura o l'utilizzazione di medicinali che contengono, consistono o derivano da tali cellule.

\section{INGEGNERIA TISSUTALE E CELLULE STAMINALI}

I principi base dell'ingegneria tissutale prevedono la combinazione di cellule vitali con una matrice naturale o sintetica al fine di generare un tessuto vitale che risulti immunologicalmente, funzionalmente, strutturalmente e meccanicamente identico al tessuto nativo.

Al fine di ottenere una restitutio ad integrum stabile e duratura, è necessario soddisfare alcuni fondamentali criteri: generare un numero di cellule, e quindi un tessuto, dalle dimensioni adeguate al singolo caso; differenziare correttamente le cellule e mantenere il corretto fenotipo; creare un agglomerato cellulare che risulti organizzato correttamente nelle tre dimensioni e che produca una matrice extracellulare adeguata; produrre cellule e tessuti adatti strutturalmente e meccanicamente alle caratteristiche del tessuto nativo; ottenere una completa integrazione con il tessuto ricevente dal punto di vista immunologico ed un'adeguata neoangiogenesi che assicuri l'integrazione anche dal punto di vista vascolare.

L'elemento chiave nel far fronte a tutti questi criteri risiede nella qualità dei materiali di partenza ed in particolar modo in un'affidabile fonte di cellule.

Lo spettro delle possibili fonti di cellule utilizzabili nell'ingegneria tissutale include cellule mature già differenziate prelevate dal paziente, cellule staminali adulte.

Nonostante la buona disponibilità e l'assenza di rea- 
zioni immunitarie avverse, le cellule mature rappresentano una buona fonte per l'ingegneria tissutale: l'alto grado di differenziazione implica una minor capacità proliferativa e restringe il campo di utilizzo al fenotipo cellulare specifico del tessuto da cui vengono prelevate.

Le cellule staminali adulte meglio caratterizzate sono quelle derivanti dal midollo osseo. Ve ne sono due tipi: le cellule ematopoietiche, che possono generare l'intera linea cellulare del sangue, e quelle dello stroma midollare o mesenchimali (MSC) che possono generare numerosi tessuti connettivi, tra cui il tessuto osseo e quello adiposo.

Tra tutte, le MSC hanno dimostrato la maggiore duttilità: nel modello animale sono risultate in grado di generare fenotipi propri del tessuto nervoso, osseo e miocardico, ma anche della linea cellulare epatica, renale, intestinale, ematopoietica e della cute. ${ }^{12-16}$

Questa straordinaria capacità differenziativa ha contribuito ad amplificare la ricerca sulle cellule staminali adulte ed intensificare il dibattito sulla necessità di ricorrere alle cellule staminali embrionali, che presentano maggiori rischi di reazioni immunologiche avverse e risultano meno prevedibili per ciò che concerne eventuali degenerazioni in senso neoplastico. ${ }^{16}$

\section{Tipologie di scaffold disponibili}

Esistono due categorie di scaffold, costituiti da materiali: naturali (collagene, glicosaminoglicani, alginati eccetera) e sintesi (polimeri, materiali ceramici, biovetri, ecc.).

I principali vantaggi dei materiali naturali sono la scarsa tossicità e la scarsa risposta infiammatoria cronica; inoltre possono essere combinati in masse composite biodegradabili, acquisendo caratteristiche meccaniche proprie dei materiali di sintesi e mantenendo caratteristiche di biocompatibilità ${ }^{7}$. Gli svantaggi includono la scarsa resistenza meccanica ed una complessità strutturale che ne rende difficile l'utilizzo e che richiede spesso una manipolazione chimica. Il collagene, principale proteina della matrice extracellulare, è uno dei biomateriali di più comune utilizzo.

Esistono tre classi principali di materiali di sintesi: i polimeri, i materiali ceramici ed i biovetri.

\section{Applicazioni cliniche}

Le principali applicazioni cliniche della rigenerazione tissutale per mezzo di scaffold interessano il tessuto osseo, il tessuto cartilagineo, il tessuto nervoso, l'apparato vascolare e la pelle.

Tessuto osseo. La resistenza meccanica rappresenta in questo caso una delle caratteristiche predominanti richieste allo scaffold, che deve essere progettabile nelle tre dimensioni, al fine di rispondere alle specifiche esigenze delle porzioni anatomiche interessate. Lo scaffold deve poi presentare una superficie porosa in grado di promuovere il pro- cesso di neoformazione ossea. Un esempio può essere lo scaffold in corallo, utilizzato su modello animale per rigenerare del tessuto osseo con cellule staminali mesenchimali; ${ }^{17}$ si tratta di un esoscheletro naturale in cui il carbonato di calcio inorganico cresce seguendo una matrice organica e presenta ottime caratteristiche meccaniche. ${ }^{18,19}$

Tessuto cartilagineo. Le peculiari caratteristiche del tessuto cartilagineo rendono molto complesse le ipotesi rigenerative.

Si tratta infatti di un tessuto non vascolare che possiede scarse capacità riparative. Uno scaffold ideale in questo caso dovrebbe impedire la trasformazione in senso fibroblastico dei condrociti, mantenendoli nel fenotipo condrogenico. Uno dei materiali proposti a tale scopo è il copolimero polilattato-poliglicolato (PGA/PLA), utilizzato con successo per rigenerare tessuto cartilagineo a partire da condrociti articolari bovini. ${ }^{20}$

Tessuto nervoso. Attualmente le tecniche di riparazione utilizzate in caso di sezione dei tronchi centrali o periferici prevedono il ricongiungimento chirurgico dei capi tagliati. La rigenerazione guidata del tronco nervoso può essere anche favorita da strutture in grado di guidare le cellule, come dei particolari polimeri in grado di promuovere l'adesione cellulare e la crescita dell'assone..$^{21}$

Apparato vascolare. L'ingegneria tissutale consente attualmente di produrre degli innesti vascolari in grado di sostituire vasi di piccolo diametro, coltivando cellule proprie del tessuto muscolare liscio in strutture tubolari di poliglicolato. ${ }^{22,23}$

Pelle. L'ingegneria tissutale rappresenta attualmente una solida alternativa nel trattamento delle lesioni da ustione. Il tessuto ottenuto con queste tecniche può essere applicato sulle ferite e favorire la fase ricostruttiva.

\section{Limiti dell'ingegneria dei tessuti}

Le potenzialità precedentemente evidenziate, studiate e sperimentate con particolare entusiasmo a partire dagli anni ' 80 con nuove tecniche di ricostruzione e rigenerazione in vitro e in vivo, si sono scontrate e si scontrano tuttora con importanti fattori limitanti.

La vascolarizzazione rappresenta un delicato problema da risolvere. Infatti, la funzionalità di cellule e tessuti dipende in maniera fondamentale dalla possibilità di essere adeguatamente ossigenati e di poter espellere e allontanare i prodotti di rifiuto risultanti dalla normale attività metabolica. Questa funzione deve essere garantita e controllata sia in fase di crescita e maturazione in vitro, sia durante l'impianto e la successiva interazione e integrazione con l'organismo. ${ }^{23-26}$ Le difficoltà insorgono non tanto nelle colture monostrato, quanto piuttosto nella coltivazione delle cellule in sistemi tridimensionali di particolare struttura geometrica e nel momento dell'impianto in vivo. ${ }^{23,25}$ Quindi i tessuti costituiti da aggregati cellulari di dimensioni consistenti non possono essere impiantati 
se non si predispone di una sede opportunamente vascolarizzata oppure della possibilità di formare nuovi vasi. Un discorso un po' diverso va dedicato all'impianto di tessuti prossimi alla parete vascolare per i quali il contatto con il sangue garantisce una adeguata ossigenazione, ma può causare problemi di deposito e formazione di trombi. A riguardo, si stanno cercando di utilizzare superfici a contatto con il sangue rivestite da cellule endoteliali del paziente, anche se le difficoltà insorgono nella loro reperibilità e resistenza meccanica al flusso sanguigno. ${ }^{23}$

In relazione a quanto appena esposto, la struttura dei tessuti biologici a livello microscopico è molto differenziata proprio in funzione della necessità di garantire il trasporto di sostanze, un'adeguata disposizione delle cellule e una risposta funzionale alla sollecitazione meccanica a cui sono sottoposte. ${ }^{23,25}$ Questa specificità strutturale rende difficile la riproduzione in laboratorio di tessuti biologici anche semplici. Si cerca, quindi, di garantire il più possibile un adeguato supporto meccanico mediante l'utilizzo di scaffold microstrutturati e di orientare la crescita e la differenziazione cellulare mediante fattori di crescita e opportuni stimoli forniti dall'ambiente di coltura. ${ }^{10,11}$

Un altro aspetto fondamentale dell'ingegneria tissutale concerne proprio la differenziazione cellulare. L'ottenimento di nuovo tessuto prevede, infatti, la differenziazione delle cellule durante la loro maturazione ed espansione in vitro su appositi scaffold.$^{10} \mathrm{Si}$ è accennato al fatto che ci sono sostanzialmente due possibilità a riguardo. ${ }^{26,27}$ La prima prevede la formazione di neo-tessuto a partire da cellule differenziate del paziente; in questo caso le cellule proliferano in vitro andando incontro a un processo iniziale di de-differenziazione a seconda delle condizioni fisico-chimiche che si sperimentano. La seconda possibilità riguarda l'utilizzo di cellule staminali indifferenziate e comporta la conoscenza adeguata e approfondita dei fattori in grado di indurre il differenziamento delle cellule utilizzate. Il percorso di ricerca è ad oggi ancora lungo e ostacolato, in parte, da problemi di natura etico-religiosa. ${ }^{25}$

Le colture cellulari sono fortemente dipendenti dai fattori di crescita che ne inducono il differenziamento e la proliferazione; i fattori di crescita sono normalmente presenti nel siero fetale utilizzato in laboratorio. ${ }^{20,25}$ Anche se la loro composizione è per la maggior parte nota, è difficile realizzare o creare in maniera artificiale una simile composizione di proteine e si deve ricorrere all'utilizzo di siero di origine animale. Anche se il materiale è di origine controllata, il suo impiego in sistemi di coltura potrebbe indurre reazioni autoimmuni o introdurre agenti patogeni o trasmettere malattie. Le normative attualmente in vigore non consentono l'impiego di prodotti di origine animale per la coltura in vitro di tessuti umani. Per questi motivi la ricerca è indirizzata a soluzioni alternative che coinvolgono la tecnica del DNA ricombinante per pro- durre fattori di crescita o l'utilizzo di siero umano del paziente stesso. ${ }^{28,29}$

Tra le difficoltà che s'incontrano nell'utilizzo clinico di tessuti sostitutivi ingegnerizzati c'è la risposta dell'organismo al materiale impiantato. Le reazioni dell'organismo all'impianto di cellule e tessuti è fondamentale per l'integrazione funzionale del neo tessuto e influenza la durata del mantenimento delle proprietà fisico-chimiche e meccaniche dello stesso, evitandone deterioramento, danneggiamento e conseguente perdita della originaria funzionalità. È necessaria una risposta o reazione da parte dell'organismo, poiché se il materiale fosse accettato dall'organismo in maniera passiva non sarebbe possibile ottenere l'interazione funzionale per la quale il tessuto è stato programmato, coltivato e impiantato. La scelta di utilizzare cellule autologhe per ingegnerizzare tessuti destinati ad uso clinico garantisce una completa accettabilità delle componenti cellulari da parte del sistema immunitario del paziente, ma non garantisce una corretta attrazione cellulare e produzione di matrice extracellulare; quanto appena detto è confermato dalla possibile, e non rara, formazione indesiderata di tessuto fibrotico attorno agli impianti. La ricerca si apre, nel tentativo di risolvere anche questo problema, alla coltivazione e differenziazione di cellule staminali adulte. In Italia non è possibile ottenere cellule staminali da embrioni umani per i problemi di natura etico-religiosa di cui si è fatto cenno in precedenza.

\section{LA MEDICINA RIGENERATIVA}

Il termine medicina rigenerativa identifica quella branca della medicina il cui obiettivo è portare al recupero permanente dei tessuti e degli organi danneggiati sfruttando le potenzialità rigenerative delle cellule staminali. Gli avanzamenti della medicina rigenerativa sono quindi strettamente correlati ai progressi delle conoscenze sulla biologia delle cellule staminali in quanto le cellule staminali ed i loro derivati specializzati, naturali o ingegnerizzati, forniscono le componenti funzionali di un regime terapeutico rigenerativo.

Due sono le strategie di intervento della medicina rigenerativa. Il primo prevede l'approccio in vivo che si basa sulla stimolazione farmacologica delle cellule staminali residenti nei tessuti endogeni d'interesse al fine di stimolarne il potenziale riparativo. Il secondo approccio, ex vivo, mira al trapianto di cellule staminali, o progenitrici, espanse e/o modificate geneticamente in vitro che vadano a colonizzare il distretto d'interesse e ne sostengano l'aspetto rigenerativo-riparativo. In questa sezione ci focalizzeremo principalmente sugli aspetti di terapia cellulare in medicina rigenerativa, tralasciando le strategie in vivo in quanto ancora difficili da immaginare a scopo terapeutico per la maggior parte delle malattie.

La Medicina Rigenerativa rappresenta il futuro degli 
approcci terapeutici, in quanto è grado di impiegare cellule, o tessuti viventi, per curare i meccanismi patologici alla base delle malattie. Molte delle patologie croniche che affliggono la popolazione potrebbero essere curate grazie a trapianti cellulari. Un sistema sanitario più sostenibile ed efficiente è dunque realizzabile grazie a questa scienza; tuttavia, affinché tale pressante necessità possa essere soddisfatta, c'è bisogno oggi di una strategia condivisa a livello nazionale, in grado di armonizzare il lavoro di ricercatori, industrie, investitori ed agenzie predisposte alla regolamentazione dei medicinali ad uso umano.

Uno dei maggiori problemi che la Medicina Rigenerativa si trova a dover affrontare è altresì rappresentato dalla regolamentazione riguardante i prodotti medicinali. Di frequente, infatti, i prodotti proposti sono talmente innovativi da rendere difficoltoso per il legislatore esprimere parere al riguardo, non potendo lo stesso trovare, nella normativa già in vigore, supporto alla propria decisione. Ruolo chiave dell'infrastruttura è rappresentato anche dalla possibilità di dialogare con i soggetti preposti alla regolamentazione della specifica materia, in modo da poter identificare il corretto iter di sviluppo che un prodotto innovativo debba seguire prima di essere commercializzato, nel rigoroso rispetto delle normative.

Oggi sono tutti concordi nel definire la Medicina e la Chirurgia Rigenerativa come un settore interdisciplinare di ricerche ed applicazioni cliniche focalizzate prevalentemente sulla prospettiva di riparare, sostituire e/o rigenerare cellule, tessuti e/o organi al fine di ripristinare alcune funzioni anatomiche, fisiologiche e biochimiche deteriorate per cause differenti, come difetti congeniti, malattie, traumi ed invecchiamento.

Gli obiettivi della Medicina e Chirurgia Rigenerativa sono piuttosto vasti; ad esempio vi si possono includere malattie croniche degenerative (come la Malattia di Alzheimer), malattie metaboliche (come il Diabete), patologie croniche osteoarticolari e malattie che spesso conducono all'insufficienza di un intero organo (insufficienza cardiaca). Appare chiaro come la medicina rigenerativa, potendo guarire/prevenire le patologie croniche, potrà rappresentare nel prossimo futuro l'ago della bilancia che permetterà agli Stati di poter sostenere i costi socio-sanitari legati all'inarrestabile aumento della vita media della popolazione.

\section{L'alba della medicina rigenerativa}

Una data importante per la medicina rigenerativa è il 1909, quando lo scienziato russo-americano Alexander A. Maximov proponeva il termine di cellule staminali, studiando le cellule progenitrici ematopoietiche. Tuttavia, solo nel 1963 a cura dei ricercatori canadesi A. Ernest McCulloch e James Till vi fu la prima descrizione quantitativa delle attività di auto-rinnovamento delle cellule trapiantate del midollo osseo nel topo.
Un'applicazione importante per la ricerca sulle cellule staminali fu il trapianto di midollo osseo con staminali adulte che, nei primi anni del 1900, i medici provarono a somministrare ai pazienti con anemia e leucemia per via orale. Esperimenti di laboratorio alla fine dimostrarono che $i$ topi con midollo alterato potevano essere curati con infusi del sangue di midollo prelevati da altri topi. Questo portò i medici a pensare che il trapianto di midollo osseo da un essere umano ad un altro (trapianto allogenico) era possibile. Tra i primi tentativi numerosi furono quelli effettuati in Francia alla fine degli anni ' 50 a seguito di un incidente nucleare. Trapianti di midollo nell'uomo su larga scala non furono comunque realizzati fino a quando nel 1958 il medico ricercatore francese Jean Dausset individuò il primo degli antigeni d'istocompatibilità umani, proteine che danno al sistema immunitario la capacità di determinare ciò che non appartiene al corpo e creare anticorpi. Per evitare il problema del rigetto, i primi trapianti di midollo furono effettuati tra gemelli, proprio perché tra loro vi è totale compatibilità immunitaria. Solo dopo studi approfonditi d'immunologia, un gruppo di medici eseguì, nel 1973, il primo trapianto tra persone senza rapporti di parentela.

Dal primo trapianto a oggi molte furono le scoperte nel campo della rigenerazione che portarono alla scoperta delle cellule staminali ematopoietiche nel cordone ombelicale umano e alla derivazione di cellule embrionali staminali di topo dalla massa cellulare interna ad opera degli scienziati Martin Evans, MatthewKaufman, e Gail R. Martin che coniò il termine cellule staminali embrionali. Infine, nel 1998, James Thompson dell'università di Wisconsin - Madison isolò le cellule staminali embrionali da blastocisti e sviluppò le prime linee di cellule staminali embrionali.

Sulle proprietà di rinnovamento il medico italiano Giulio Bizzozero fondò una duratura classificazione dei tessuti dell'organismo umano - labili, stabili, perenni - avendo compreso che la vita di un organismo è legata a un processo continuo, fisiologico di rigenerazione che vale a conservarne immutate la costituzione e le proprietà.

La diversità di nomi rifletteva la progressiva specializzazione delle scienze della vita, conservatasi praticamente immutata fino a pochi anni fa. La diversità terminologica derivava inoltre dalle peculiari potenzialità delle cellule staminali conosciute: a seconda degli organismi e dei tessuti in cui venivano osservate, veniva loro dato un nome.

Tuttavia sulla loro funzione vi era poco dubbio, e già negli anni Dieci era chiaro che la loro destinazione finale, cioè il tessuto cui davano vita, fosse dovuta a fattori estrinseci alle cellule staminali.

Fattori costanti, che nella rigenerazione fisiologica replicavano la determinazione che avviene nell'ontogenesi, e che determinano il comportamento di queste cellule dalla potenzialità istogenetica multipla. Sono queste cellules-souches, una categoria di elementi a potenzialità 
istogenetica multipla perché scappate alla determinazione istogenetica che avviene nell'embrione, ad avere il ruolo principale nella rigenerazione fisiologica.

Rimaneva il mistero di quali fossero i fattori che determinavano l'espressione della potenzialità delle cellule. Mentre i primi misero a punto sistemi sempre più fini per evidenziare la gerarchia dei sistemi di sviluppo, con alcuni tessuti in grado di determinare il destino degli altri, Morgan cercò la risposta nel materiale contenuto nelle cellule, di fatto dando il via alla ricerca genetica sui cromosomi.

Le cellule staminali, come concetto biologico, hanno quindi un'origine storica variegata. Lo studio delle cellule della rigenerazione è stato affiancato alla fine dell'Ottocento dalla ricerca sulle cellule dei tessuti adulti. Questo approccio si è rivelato il più fruttuoso in termini di comprensione dei meccanismi eziopatologici di diverse malattie.

Non sempre infatti le cellule staminali di un tessuto, se reinfuse in un paziente, riescono a differenziare in tutte le cellule necessarie a una rigenerazione completa. Il controllo di questi processi è all'oggi ancora estremamente limitato, anche per le cellule meglio caratterizzate. Il primo esempio di terapia con cellule staminali, usato da decenni, è il trapianto di cellule staminali ematopoietiche, detto anche trapianto di midollo osseo. In questa procedura, il midollo viene prelevato dal donatore, e da questo tessuto si prelevano le cellule staminali, per reinfonderle nel paziente ricevente. Nonostante queste cellule siano note e utilizzate da molto tempo, l'espansione in vitro di questo particolare tipo cellulare (che garantirebbe una maggiore efficacia ai trapianti) continua ad essere estremamente difficile. Un'altra applicazione efficace della terapia cellulare si basa sull'uso delle cellule staminali della pelle, messo a punto da Howard Green nel 1983 per il trattamento dei grandi ustionati.

Cellule staminali sono state utilizzate anche per trattare i pazienti la cui cornea è stata danneggiata da ustioni chimiche estese. Applicazioni più spettacolari, ma comunque ancora lontane dalla clinica vengono dalla cosiddetta ingegneria dei tessuti. In questo campo ci si sta attrezzando per produrre interi organi, nella loro intera struttura tridimensionale, e alcuni risultati preliminari ne hanno mostrato la fattibilità. Tuttavia, è ancora lungo il percorso per arrivare a un loro utilizzo terapeutico, dovendo superare i problemi legati all'inserimento fisiologicamente funzionale degli organi prodotti all'interno dell'organismo.

La medicina rigenerativa, ormai istituzionalizzata ad ogni livello, avrà la possibilità di ricambiare le tante speranze suscitate nel pubblico solo se sarà in grado di muoversi nel solco della tradizione storica che è stata tracciata: l'intreccio di tanti e diversi filoni di ricerca, ognuno con il proprio bagaglio di conoscenze, tecniche e approcci. Una molteplicità in grado di affrontare ad ogni livello le questioni della rigenerazione terapeutica per l'organismo umano, così da comprenderne i meccanismi e mettere a punto trattamenti efficaci. Rinunciare a integrare le diverse prospettive significherebbe privare la pratica clinica di fondamenti biologici, aprendo le porte a una medicina empirica incapace di produrre nuove conoscenze e di indicare le strade più promettenti, e rischiando di trasformarsi in una pratica sempre meno scientifica. Ma è proprio questa capacità di connettere biologia e medicina che rappresenta la nostra tradizione medica, e in ultima analisi ci fornisce gli strumenti per distinguere le buone pratiche cliniche dalle illusioni parascientifiche.

\section{Cellule staminali in biologia e nella medicina rigenerativa}

Normalmente lo sviluppo dei mammiferi procede a senso unico, con cellule dapprima immature che successivamente si specializzano (differenziano), diventano meno versatili, e quindi popolano e costruiscono i nostri tessuti. È infatti solo in una breve finestra temporale, e cioè nelle prime fasi dello sviluppo, precisamente allo stadio di blastocisti, che tutte le cellule hanno la capacità di trasformarsi in uno qualsiasi dei 220 tipi cellulari del corpo umano, dalle cellule cardiache ai neuroni alle cellule della pelle.

Nelle successive fasi dello sviluppo dell'embrione impiantato, quindi allo stadio fetale, le cellule staminali che popolano i tessuti in via di formazione sono già specializzate avendo acquisito identità e potenzialità differenziative più ristrette e tipiche del tessuto in cui risiedono. Queste staminali sono anche dette staminali somatiche, o tessutali o fetali ma a volte le si trova raggruppate anche alla voce staminali adulte, intese come cellule staminali dei tessuti già specializzati.

Queste cellule garantiscono l'espansione numerica e la specializzazione necessaria alla formazione dei diversi tessuti di un individuo.

Nell'individuo formato, cellule staminali adulte continuano a popolare i diversi organi e tessuti, dovendo garantire quel ricambio cellulare necessario per la funzionalità dell'organo e la sopravvivenza dell'organismo. In questi singoli tessuti o organi adulti, la presenza di staminali sarà tanto più abbondante quanto maggiore è la necessità e la capacità rigenerativa del tessuto in questione. Le staminali adulte sono quindi molto diverse tra loro, come localizzazione, abbondanza e specializzazione, dovendo generare tessuti diversi.

Sono queste capacità delle cellule staminali, cioè la loro propensità all'autorinnovamento nonchè la potenzialità differenziativa (diversa per le diverse staminali) ad attirare 1'attenzione della ricerca. Questo interesse è soprattutto determinato dalla possibilità e dalla speranza di un loro impiego a livello clinico per trapianti riparativi. 


\section{Le staminali adulte, un'inesauribile fonte endogena}

Da sempre le cellule staminali adulte attirano l'interesse della ricerca di base e clinica per il fatto di essere tessuto specifiche quindi in un certo senso già specializzate, di essere endogene e quindi fisiologicamente rilevanti oltre che di più facile accesso rispetto alle embrionali. Ad esempio, l'estrema propensione rigenerativa del sangue nell'adulto è garantita da una inesauribile riserva di cellule staminali ematopoietiche professioniste che risiedono nel midollo osseo delle ossa piatte. Ogni giorno, queste cellule sono capaci di produrre 2,5 MLD di eritrociti, 2,5 MLD di piastrine e 1 MLD di leucociti per kg di peso corporeo per sostituire quelle usurate. Un altro tessuto ricco in staminali è l'epidermide la quale, ogni minuto, perde (e deve rigenerare) 30x103 cellule del suo strato più superficiale per permettere al nostro organismo di vivere. Si può quindi calcolare che ogni 3 settimane l'epidermide si rigenera. Anche la cornea ha un'intensa capacità rigenerativa, praticamente ogni due settimane si forma nuova cornea.

Queste evidenze indicano che cellule con caratteristiche di staminali esistono in vivo nell'adulto e in molti casi assolvano a funzioni rigenerative importanti.

Tuttavia è bene ricordare che i protocolli per il loro isolamento da tessuto restano ancora primitivi - eccetto per sangue e pelle per le quali, soprattutto per quest'ultima, notevoli passi sono stati fatti in merito alla loro espandibilità.

Questo significa che la possibilità di sfruttare la differente capacità rigenerativa delle staminali endogene portandole in laboratorio al fine di produrne in grande quantità, migliorandone le caratteristiche senza che perdano quelle fisiologiche desiderate (come la capacità differenziativa) rappresenta ancora terreno esplorato finora con scarsi risultati, con alcune rare eccezioni.

\section{Approcci di medicina rigenerativa per il trattamento delle lesioni degli epiteli di rivestimento}

Uno degli ambiti con sicure applicazioni cliniche oggi è quello della riparazione degli epiteli squamosi. Questi includono l'epidermide e la cornea. In questi casi, già da diversi anni è possibile effettuare dei trapianti di pelle autologa.

Il nuovo tessuto cutaneo viene generato in vitro su matrici di collagene e matrigel, a partire da progenitori e staminali cutanee derivanti da piccole biopsie della cute del paziente. Pioniere di questo filone di ricerca è stato Howard Green. Fu proprio Green, a Boston nel 1983, a eseguire il primo trapianto di pelle coltivata su tre bambini ustionati gravi. ${ }^{6} \mathrm{Da}$ allora centinaia di pazienti hanno beneficiato di questo trattamento salvavita che viene applicato ai pazienti con ustioni di terzo grado. Tuttavia la letteratura è priva di informazioni circa i meccanismi alla base dell'integrazione del nuovo tessuto. Ancora oggi, quindi, predire l'efficacia di un trapianto è impossibile e le linee guida per il trapianto non si sono evolute in modo significativo negli ultimi 25 anni.

Ciononostante nel 1987 uno studio di Yann Barrandon ha proposto una metodologia efficiente per la crescita di cellule staminali della pelle in vitro e la produzione di cheratinociti a partire da esse, anche se i costi elevati e la necessità di diversi mesi per ricostruire lembi di pelle estesi, di fatto ne limitano la piena diffusione in clinica. In aggiunta, sebbene questo oggi rappresenti uno straordinario trattamento salvavita, i malati trapiantati chiedono una vita migliore. La pelle così rigenerata, infatti, non è ottimale in quanto priva di ghiandole sudoripare e di bulbi piliferi. La pelle inoltre è secca, provocando anomalie nella termoregolazione e nella fisiologia di questo importante tessuto.

Ecco quindi che è necessario capire la normale fisiologia di sviluppo e rigenerazione della pelle e capire la biologia delle staminali della pelle. Oggi sappiamo che le staminali cheratinocitiche sono localizzate in diverse zone dell'epidermide. Queste cellule si propagano generando olocloni che possono sostenere anche 200 divisioni e che quando trapiantati riescono a rigenerare pelle o cornea. Altre staminali sono presenti nel bulbo pilifero e nelle ghiandole sudoripare. Quelle del bulbo pilifero sembra partecipino attivamente anche alla riparazione dell'epidermide in seguito a danno.

Un altro epitelio che è possibile rigenerare completamente in vitro è l'epitelio corneale. ${ }^{30}$ In caso di lesioni alla cornea, l'epitelio congiuntivale, che costituisce la parte visibile bianca dell'occhio, prende il sopravvento portando alla formazione di quello che in termini clinici si chiama pannus e che copre tutto il bulbo, causando cecità. In molti casi, è possibile ricostruire la cornea partendo da staminali presenti a livello del limbus dell'occhio, una striscia di cellule, di cui circa il $10 \%$ con caratteristiche staminali, che circonda la cornea. Sebbene il prelievo non possa essere mirato al prelievo delle sole staminali limbari, è presumibile che il sistema di espansione in vitro selezioni per le staminali corrette le quali, una volta messe in coltura, sono in grado di ricostruire in circa 3-4 settimane un lembo di epitelio corneale che viene impiantato al posto di quello compromesso.

In conclusione, i riflettori puntati sulle staminali devono anche portare scienziati, medici, enti regolatori e bioeticisti ad agire in modo coordinato, per potere procedere verso una responsabile traslazione della ricerca sulle cellule staminali in applicazioni cliniche appropriate e basate sull'evidenza.

\section{LE CELLULE STAMINALI}

Le cellule staminali sono cellule non specializzate presenti in tutti gli organismi viventi. Diversamente da una cellula epiteliale, capace di produrre una barriera biolo- 
gica a difesa del nostro organismo, o da un globulo rosso, in grado di trasportare l'ossigeno attraverso il circolo sanguigno, una cellula staminale non possiede alcuna specializzazione fisiologica. La definizione di cellula staminale si basa essenzialmente su due caratteristiche: $a$ ) autorinnovamento, ossia la capacità di generare una cellula indifferenziata esattamente uguale alla cellula-madre attraverso numerosi cicli cellulari; $b$ ) potenza, vale a dire la capacità di differenziarsi in tipi cellulari specializzati.

Si distinguono diversi stadi di potenza delle cellule staminali: la totipotenza è la capacità di generare tutti i tessuti embrionali ed extraembrionali, tipica delle cellule della morula; la pluripotenza è la capacità di differenziarsi in tutti i tessuti embrionali, tipica delle cellule staminali embrionali (ES, Embryonic Stem cells) che compongono la massa cellulare interna della blastocisti, capacità che recentemente è stata riferita anche a cellule somatiche riprogrammate; la multipotenza è la capacità di differenziare in tutti i tipi cellulari di un foglietto germinativo (endoderma, mesoderma o ectoderma); l'unipotenza è la capacità di differenziarsi in un unico tipo cellulare, tipico dei progenitori. In questo saggio verranno descritte le cellule staminali embrionali e adulte fino alle innovative cellule staminali pluripotenti indotte (iPS, induced Pluripotent Stem cells), la sfida scientifica del nuovo secolo.

\section{Cellule staminali adulte}

Una cellula staminale adulta (ASC, Adult Stem Cell) è una cellula indifferenziata che si può trovare in un tessuto o organo terminalmente differenziato; esse sono presenti in un numero molto piccolo in ogni tessuto. Si ritiene che queste cellule risiedano in aree specifiche, dalla citoarchitettura definita, che garantiscono un microambiente controllato biochimicamente, detto nicchia, dove le ASC rimangono relativamente quiescenti fino a che non vengono riattivate da un danno o da uno stato patologico. Esse proliferano durante l'intera vita di un organismo e in vitro vanno incontro a senescenza perdendo la capacità di proliferare dopo $100 \div 200$ cicli cellulari. Il ruolo primario delle cellule staminali adulte è infatti quello di mantenere il normale turnover e riparare il tessuto in cui si trovano, oltre a contribuire allo sviluppo postnatale dell'individuo. I tessuti adulti per cui è stata dimostrata l'esistenza delle cellule staminali sono molti: per es., l'endotelio, il muscolo scheletrico, il fegato, la polpa dentale, la cornea. Tipicamente le ASC sono definite multipotenti, poiché possiedono la capacità di generare tutti i tipi cellulari specializzati del tessuto d'appartenenza. Esse si dividono secondo due principali modalità: divisione simmetrica, che permette la generazione di due cellule staminali identiche tra loro; e divisione asimmetrica, che permette la generazione di una cellula staminale identica alla cellula di partenza e di una cellula progenitrice. I progenitori hanno una capacità rigenerativa inferiore a quella delle cellule sta- minali di partenza e possiedono un commitment, cioè un programma che li induce a differenziarsi in un determinato tipo cellulare. ${ }^{31}$

\section{Passato e presente}

Negli anni Sessanta del $20^{\circ} \mathrm{sec}$. alcuni ricercatori scoprirono che il midollo osseo contiene almeno due tipi di cellule staminali. La prima popolazione scoperta, le cellule staminali emopoietiche, dà origine a tutte le cellule del sangue. Pochi anni dopo fu scoperta una seconda popolazione, le cellule stromali del midollo osseo. Questa è una popolazione cellulare mista che genera l'osso, la cartilagine, il grasso e il tessuto connettivo e fibroso. Sempre negli stessi anni furono identificate alcune cellule in divisione in due aree del cervello di ratto. Nonostante questi dati, la maggior parte dei ricercatori non credeva che le cellule nervose potessero essere rigenerate nel cervello adulto. Soltanto negli anni Novanta fu accettata nel mondo scientifico la presenza di cellule staminali nel cervello, capaci di generare i tre tipi cellulari principali dell'encefalo: i neuroni, che costituiscono le cellule nervose, gli astrociti e gli oligodendrociti, che fungono invece da supporto. A partire da quel momento numerosi gruppi di ricerca si sono dedicati allo studio delle ASC e sono stati condotti indagini precliniche su modelli animali per la terapia cellulare in tessuti danneggiati o malati. Alcuni esempi di potenziali applicazioni delle ASC in terapia includono la sostituzione delle cellule dopaminergiche nell'encefalo dei pazienti malati di Parkinson, il trapianto di cellule capaci di produrre insulina (cellule beta) nel pancreas in pazienti affetti da diabete di tipo 1, la ripopolazione del tessuto muscolare scheletrico nei pazienti con distrofia muscolare di Duchenne tramite l'iniezione di precursori del muscolo scheletrico da donatore sano oppure modificati geneticamente, e la riparazione del muscolo cardiaco in seguito a infarto mediante l'iniezione di cellule muscolari cardiache. ${ }^{32}$

\section{Plasticità}

Molti esperimenti hanno recentemente dimostrato che alcune cellule staminali adulte, oltre a differenziarsi nei tipi cellulari specializzati derivanti dal foglietto embrionale d'appartenenza (il cosiddetto differenziamento ortodosso), possiedono la capacità di generare cellule specializzate di tessuti diversi. Questa proprietà è nota come plasticità, o transdifferenziamento o differenziamento non ortodosso. Attualmente la ricerca è rivolta a determinare quali siano i meccanismi responsabili della plasticità delle ASC. Se questi meccanismi verranno compresi, in modo tale da poter essere controllati, le cellule staminali da un tessuto sano potranno essere indotte a ripopolare un tessuto danneggiato. Recentemente anche nei tumori sono state identificate cellule in grado di soddisfare 
i criteri di staminalità, denominate cellule staminali tumorali (CSC, Cancer Stem Cells). Le CSC sembrano essere responsabili delle recidive e delle metastasi, e per questo motivo rappresentano un importante target ai fini dello sviluppo di terapie antitumorali.

\section{Cellule staminali dell'epidermide}

L'epidermide, lo strato più esterno della pelle, è costituito da un epitelio stratificato squamoso caratterizzato da un tipo cellulare principale, i cheratinociti. Sono stati identificati tre diversi tipi di cheratinociti, gli olocloni, i merocloni e i paracloni. L'oloclone possiede il più alto potenziale proliferativo (120-160 divisioni cellulari), è in grado di generare tutti i tipi cellulari del tessuto di origine e di recuperare in modo permanente l'epitelio quando trapiantato in pazienti con danni e difetti estesi. Per questo motivo l'oloclone è considerato la cellula staminale epiteliale. Nella pelle umana gli olocloni sono distribuiti uniformemente nello strato basale dell'epidermide interfollicolare e in specifiche regioni dei follicoli. Gli olocloni si localizzano anche nell'epitelio del limbus oculare, compreso tra la cornea e la congiuntiva bulbare. Durante il normale turnover dell'epidermide, gli olocloni entrano nel programma differenziativo, perdono la loro capacità proliferativa (meroclone, paraclone), migrano verso lo strato più esterno dell'epidermide e attivano il processo di morte cellulare programmata, dando origine allo strato spinoso, allo strato granuloso e allo strato corneo dell'epidermide. Il paraclone possiede una ridotta capacità proliferativa rispetto all'oloclone (15 divisioni cellulari) e nel processo di divisione cellulare genera solo cellule terminalmente differenziate. Il meroclone può essere considerato una stadio cellulare intermedio tra l'oloclone e il meroclone. Un oloclone può essere quindi prelevato dalla pelle e amplificato estensivamente in vitro tanto da poter essere utilizzato per il trapianto di un'estesa superficie epidermica.

\section{Applicazioni cliniche}

I cheratinociti dell'epidermide possiedono due importanti caratteristiche: l'elevata capacità replicativa e la facile reperibilità. ${ }^{33,34}$ Queste cellule sono state utilizzate nella cura di gravi ustioni. A partire da cheratinociti autologhi è possibile produrre in vitro l'epitelio stratificato della pelle e, successivamente, innestarlo nel paziente ustionato. In maniera simile è possibile isolare cellule staminali epidermali dall'estremità del canale uretrale, farle crescere in vitro e utilizzarle per ricostituire la porzione mancante dell'uretra. Le cellule progenitrici della cornea, localizzate nell'epitelio del limbus, si possono isolare e coltivare per generare l'epitelio corneale da trapiantare in caso di necessità. Cellule staminali dell'epidermide hanno inoltre trovato impiego, con successo, nella cura di alcune malattie degli epiteli, come l'epidermolisi bullosa che comprende un gruppo di gravi malattie ereditarie della pelle causate dalla mutazione del gene della laminina $5 \mathrm{o}$ di altri componenti dell'emidesmosoma: cellule staminali dell'epitelio umano sono state coltivate e stabilmente trasdotte in vitro con vettori retrovirali, codificanti per la proteina sana della laminina 5; le cellule corrette geneticamente riacquistano le proprietà adesive tipiche delle cellule sane e sono in grado di esprimere il transgene per lungo tempo. È stato, quindi, messo a punto un protocollo clinico per il trapianto, sotto anestesia locale, di strati epiteliali geneticamente corretti su regioni del corpo piuttosto vaste, ottenendo risultati molto incoraggianti. ${ }^{35}$

\section{Meccanismo d'azione della terapia cellulare}

Sebbene siano stati effettuati grandi passi avanti nella ricerca terapeutica per le malattie cardiovascolari, il meccanismo attraverso il quale la terapia cellulare può apportare un beneficio alla funzione cardiaca non è ancora molto chiaro. Tre sono le teorie più accreditate: fusione cellulare, transdifferenziamento e rilascio di mediatori paracrini.

La fusione cellulare consiste nell'unione di una cellula ospite con la cellula staminale trapiantata, con conseguente trasferimento del contenuto cellulare e delle informazioni necessarie per svolgere le funzioni cellulari. Sten Eirik Jacobsen e altri ricercatori hanno dimostrato che trapiantando progenitori ematopoietici, alcuni di essi si fondono con le cellule del muscolo cardiaco, anche se con una frequenza bassissima. Il termine transdifferenziamento indica invece la capacità di una cellula staminale residente in un tessuto di differenziarsi in cellule presenti in altri tessuti. Altra modalità che potrebbe spiegare gli effetti benefici della terapia cellulare nelle patologie cardiache è il rilascio paracrino di fattori di crescita e di sopravvivenza. In questo caso la cellula trapiantata apporta effetti benefici attraverso la liberazione di citochine e fattori di crescita in grado di stimolare la sopravvivenza delle cellule differenziate e il differenziamento delle cellule staminali residenti. È molto probabile che questi tre meccanismi non agiscano in modo separato ed esclusivo, ma si manifestino sinergicamente per aumentare la rigenerazione del miocardio danneggiato.

\section{LA RIGENERAZIONE MEDIANTE L'UTILIZZO DI CELLULE STAMINALI DI ORIGINE ADIPOSA}

Le cellule staminali mesenchimali umane (hMSCs) possono essere ottenute, oltre che dal midollo osseo, fonte classica iniziale di isolamento, anche da fonti alternative quali la polpa dentaria, le membrane fetali della placenta a termine e il tessuto adiposo (adipose derived stem cells, hASCs). Tali cellule sono in grado di riprodurre processi 
di vasculogenesi e differenziamento cardiovascolare in vitro, e possono essere anche utilizzate in vivo, per promuovere la riparazione di cuori danneggiati in animali sottoposti ad infarto miocardico, ${ }^{22}$ o per migliorare la rivascolarizzazione e la funzionalità di isole pancreatiche in ratti diabetici. ${ }^{24}$ Questi risultati rappresentano una prova di principio del fatto che, indipendentemente dal tessuto di provenienza, l'orientamento verso un destino vasculogenico e la riparazione vascolare in vitro ed in vivo rappresentano un comune denominatore caratterizzante della potenzialità terapeutica tissutale delle hMSCs.

Indipendentemente dalla loro fonte, hMSCs di diversa origine condividono la caratteristica di poter esprimere una insieme di fattori trofici (secretoma) secernibili in diverse condizioni ambientali di coltura in vitro e di contesto tissutale in vivo. Tali fattori individuano una peculiarità di tipo paracrino delle hMSCs che divengono così capaci di agire attraverso il loro secretoma nella sede del trapianto, inducendo risposte angiogenetiche, antiapoptotiche ed antifibrotiche.

Sebbene il midollo osseo sia stato utilizzato in passato come fonte principale di hMSCs, il prelievo di tale tessuto risulta invasivo e doloroso, ponendo la necessità della identificazione di fonti alternative di hMSCs. Inoltre, l'uso di hMSCs di origine midollare è potenzialmente gravato da un elevato grado di infezioni virali e da un significativo declino della vitalità e della potenzialità differenziativa delle stesse hMSCs con il progredire dell'età del donatore. Per questi motivi, una fonte ideale di hMSCs dovrebbe: i) essere reperibile in grande quantità; ii) essere recuperabile con una procedura minimamente invasiva; iii) rendere disponibile una popolazione di hMSCs capace di mantenere una buona vitalità ed un potenziale differenziativo elevato anche all'aumentare dell'età del donatore. ${ }^{26}$

Negli ultimi anni è diventato sempre più evidente come il tessuto adiposo possieda una popolazione di cellule staminali multipotenti, definite appunto come hASCs. Le hASCs rappresentano uno strumento promettente di terapia cellulare, dal momento che possono essere utilizzate in vivo in modelli animali di infarto miocardico acuto. Al riguardo, hASCs poste in coltura sono risultate in grado di riparare il tessuto miocardico infartuato, agendo come sorgenti paracrine di mediatori trofici di processi angiogenici. ${ }^{36}$ Le hASCs possono anche essere indirizzate verso il destino endoteliale e quello muscolare liscio. Vi sono crescenti evidenze in vitro ed in vivo che dimostrano la multipotenza delle ASCs di origine umana e di altre specie. Tali evidenze riguardano la capacità delle ASCs di intraprendere l'orientamento verso i destini adipocitario, condrocitario, ematopoietico, epatocitario, simil-neuronale, osteoblastico, pancreatico e muscolo scheletrico, oltre ai già citati orientamenti in senso miocardico e vascolare.

Malgrado i progressi nell'isolamento delle hASCs, una serie di problematiche restano ancora irrisolte, quali la sopravvivenza cellulare nulla o comunque trascurabile dopo congelamento e scongelamento del lipoaspirato, la difficoltà di espansione ex vivo, la scarsa efficienza del delivery tissutale, (meno del 5\% delle cellule trapiantate sono trattenute nel tessuto dopo trapianto), e l'incerto destino, anche differenziativo in vivo.

Queste problematiche minimizzano i vantaggi ottenibili dalla stessa espansione cellulare. Inoltre, l'opportunità di un trasferimento in ambito clinico di cellule staminali sottoposte a manipolazione rilevante, includente l'espansione ex vivo in coltura, è notevolmente ritardata dalla necessità di conformarsi ai requisiti stabiliti dalle linee guida previste per le manipolazioni cellulari maggiori in accordo con le cosiddette vigenti buone pratiche di fabbricazione (current Good Manufacturing Practice, cGMP). ${ }^{37,38}$ Tuttavia, tali restrizioni non si applicano in caso di manipolazione non rilevante. ${ }^{39}$ Da queste considerazioni emerge come sarebbe altamente auspicabile per un rapido sviluppo clinico della Medicina Rigenerativa la realizzazione di tecnologie di processazione basate su una manipolazione non rilevante atte ad ottenere idonei prodotti contenenti hASCs, pronti per l'uso autologo senza alcuna espansione, ma anche suscettibili di criopreservazione ed eventuale espansione in vitro.

\section{L'ANGIOGENESI NELLA RIGENERAZIONE TISSUTALE}

La rigenerazione dei tessuti dipende strettamente dagli stimoli e dai segnali derivanti dal microambiente presente nel tessuto stesso. Un approccio utile e meno complesso rispetto al trapianto cellulare, per l'identificazione di nuove strategie terapeutiche, consiste nella mobilizzazione delle cellule endogene. Tale metodo permette di superare le difficoltà associate all'utilizzo delle cellule staminali embrionali e/o adulte. Nonostante tale approccio sia molto promettente, al fine di individuare strategie terapeutiche di successo, è necessario ottenere una comprensione più dettagliata della complessa rete che comprende i diversi tipi di cellule e fattori coinvolti nel processo rigenerativo. ${ }^{40}$

Infatti, l'induzione all'attivazione e alla mobilizzazione delle cellule staminali endogene implica anche lo studio delle altre componenti essenziali del tessuto e delle popolazioni di cellule che promuovono l'infiammazione, la rigenerazione e l'angiogenesi. ${ }^{41}$

Il muscolo scheletrico è caratterizzato dalla notevole capacità di rigenerare dopo aver subito lesioni o come conseguenza di malattie. La rigenerazione viene avviata da tutti i segnali che vengono rilasciati sia dalle fibre danneggiate che dai macrofagi (MPs) e che portano all'attivazione delle cellule satelliti quiescenti, cioè le cellule staminali primarie che sono tra i principali fattori respon- 
sabili della rigenerazione del muscolo ${ }^{42}$ Studi recenti evidenziano che i fattori prodotti durante il processo infiammatorio possono influenzare la rigenerazione del muscolo scheletrico stimolando la sopravvivenza delle cellule satelliti e/o la loro proliferazione, mettendo in evidenza l'importanza del microambiente che è in grado di mediare la mobilizzazione delle cellule satelliti e l'induzione della rigenerazione muscolare. ${ }^{41,43}$

Tra gli scopi di questo progetto è lo studio dell'effetto di modulatori dell'angiogenesi e/o della mobilizzazione delle cellule staminali muscolari (cellule satelliti) nella rigenerazione del muscolo scheletrico, con il fine ultimo di definire nuovi protocolli di rigenerazione muscolare, basati sulla somministrazione in vivo, in modelli di danno muscolare acuto, di piccole molecole/peptidi, anche mediante l'utilizzo di biomateriali. In particolare, sarà analizzato l'effetto di un nuovo fattore, Cripto che agisce come regolatore delle cellule staminali pluripotenti, ${ }^{44,45} \mathrm{e}$ la cui espressione è indotta nelle cellule staminali e nelle cellule infiammatorie durante le fasi precoci della rigenerazione muscolare, come recentemente dimostrato nel nostro laboratorio.$^{46}$ Inoltre, sarà studiato il ruolo di Cripto sulla migrazione delle cellule satelliti. Ad oggi, infatti, le molecole ed i meccanismi relativi alla migrazione in vivo di queste cellule e dei precursori dei mioblasti sono, come la maggior parte degli aspetti della fisiologia delle cellule satellite, complicati dalla rarità e dalla dispersione delle stesse all"interno del tessuto. È necessario quindi sviluppare nuovi protocolli sperimentali, basati sulla microscopia time-lapse, che permettano di seguire il movimento delle cellule satellite e dei precursori muscolari direttamente su fibre muscolari isolate.

Il muscolo scheletrico è caratterizzato dalla notevole capacità di rigenerare dopo aver subito lesioni o come conseguenza di malattie. La rigenerazione viene avviata da tutti i segnali che vengono rilasciati sia dalle fibre danneggiate che dai macrofagi (MPs) e che portano all'attivazione delle cellule satelliti quiescenti, cioè le cellule staminali primarie che sono tra i principali fattori responsabili della rigenerazione del muscolo scheletrico. Studi recenti evidenziano che i fattori prodotti durante il processo infiammatorio possono influenzare la rigenerazione del muscolo scheletrico stimolando la sopravvivenza delle cellule satelliti e/o la loro proliferazione, mettendo in evidenza l'importanza del microambiente che è in grado di mediare la mobilizzazione delle cellule satelliti e l'induzione della rigenerazione muscolare.

\section{UTILIZZO DI PICCOLE MOLECOLE PER REGOLARE LA PROLIFERAZIONE E IL DIFFERENZIAMENTO DI CELLULE STAMINALI}

Una delle principali sfide della medicina rigenerativa è quella di poter sfruttare pienamente le multipotenzialità delle cellule staminali per permettere il ripristino, il mantenimento e/o l'aumento delle funzioni dei tessuti. Le cellule staminali possono essere sorgente di differenti tipi cellulari, compensando in tal modo l'incapacità dell'organismo adulto di riparare i danni a carico di tessuti che hanno perduto la capacità di rinnovarsi. ${ }^{47}$ In questo contesto, le ripercussioni applicative delle metodiche volte al differenziamento controllato di cellule staminali sono dunque potenzialmente enormi, in quanto utilizzabili per la cura e la terapia di un ampio spettro di patologie degenerative. Ciononostante la disponibilità di molecole in grado di controllare la loro proliferazione, il loro differenziamento, la loro motilità, ecc. è ancora molto limitata. In gran parte, ciò è dovuto: alla complessità dei meccanismi molecolari che regolano tali funzioni; alle limitazioni degli approcci sperimentali utilizzati.

La possibilità di indirizzare in maniera razionale il differenziamento di cellule staminali alterando il signaling mediante l'aggiunta di piccole molecole rappresenterebbe un sostanziale passo avanti per gli obiettivi della medicina rigenerativa. Il raggiungimento di quest'obiettivo potrebbe contribuire ad ottenere colture cellulari differenziate in maniera omogenea a costi ridotti.

\section{MEDICINA RIGENERATIVA NELLA RIPARAZIONE DELLA CUTE}

La possibilità di riparare estese soluzioni di continuo a livello cutaneo ha sempre rappresentato un problema di vitale importanza in medicina; infatti la perdita dell'integrità dell'organo deputato alla protezione dagli insulti esterni espone l'organismo ad una serie innumerevole di rischi di perdita dell'omeostasi, nonché all'aggressione da parte di microrganismi. Le soluzioni di continuo cutanee vengono, quindi, protette con cute allogenica da donatore cadavere o con costrutti autologhi ottenuti mediante processi di espansione cellulare. Per l'allestimento della coltura di cellule, è necessario un prelievo di tessuto da paziente o donatore. Il prelievo viene eseguito su una zona corporea piana, evitando le superfici articolari, il volto e le mani. Il prelievo del paziente ustionato viene effettuato preferibilmente entro il secondo giorno dal ricovero del paziente. Seguendo protocolli di disinfezione e trasporto del campione di tessuto, la biopsia viene lavorata e con l'utilizzo di enzimi, vengono separate le cellule del derma e dell'epidermide.

Si procede alla coltura in terreno specifico, alla crescita cellulare in appositi incubatori e, dopo circa 3 settimane le cellule vengono seminate su appositi sostegni (scaffold o lamine) utilizzati per veicolare le cellule in sede di lesione.

Essi, infatti, possono essere posizionati direttamente sulla zona da trattare oppure crioconservati in appositi container per essere utilizzati in un tempo successivo se- 
condo necessità. Dal punto di vista chirurgico, il principale vantaggio della coltivazione epiteliale è che una vasta superficie di sostituto cutaneo può essere prodotta per coprire le aree cruente: un frammento bioptico di $2 \mathrm{~cm}^{2}$ può essere fatto espandere fino ad una superficie 10.000 volte maggiore in 3-4 settimane.

L'entusiasmo e l'ottimismo sono aspetti importanti della ricerca, dell'innovazione e del progresso. Possono, infatti, generare una forza costruttiva che aiuta ad attirare finanziamenti indispensabili per la ricerca scientifica.

Ma il clamore, quando diventa esagerato e scientificamente insostenibile, si tramuta in speculazione e nel complesso non può essere visto come una forza positiva.

La ricerca sulle cellule staminali, ad esempio, ha generato molta attenzione da parte dei media, allontanandosi dalle discussioni di ordine etico in favore di un'immagine positiva per innumerevoli potenziali applicazioni terapeutiche. ${ }^{48}$

Questo aumenta il rischio di conseguenze dannose perché crea aspettative non realistiche e fuorvianti che generano un profondo divario tra la percezione della gente e il reale stato della ricerca.

Tra l'altro, ultimamente è stato osservato un diffuso utilizzo di un linguaggio sensazionalistico anche negli abstract peer-reviewed e nei comunicati stampa istituzionali, che dovrebbero invece mantenere uno stile sobrio e aderente alla realtà. ${ }^{49}$

Ma tutto il resto va riconosciuto presentando i progressi scientifici con argomentazioni che non siano emotive o emozionali, nel rispetto dei tanti ricercatori che con impegno, passione e rigore, contribuiscono a sviluppare metodi e farmaci utili a donare speranza ai malati e alle loro famiglie.

In considerazione di ciò e per combattere il diffondersi di false promesse proteggendo i pazienti da notizie su possibili terapie non ancora consolidate, l'International Society for Stem Cell Research (ISSCR) ha stilato delle raccomandazioni contro gli inganni sulle terapie con staminali.

A firmare le linee guida sono più di trenta specialisti, tra cui bioeticisti e tecnici, con un vademecum che serve a mettere in guardia i pazienti consentendo loro di distinguere tra le sperimentazioni che hanno un fondamento scientifico e quelle basate su pericolose illusioni. Un ulteriore obiettivo delle linee guida è quello di fare chiarezza sulle potenzialità terapeutiche delle staminali adulte e di quelle embrionali.

Sono inoltre presenti raccomandazioni per aiutare i ricercatori a non confondere il linguaggio della ricerca con quello della cura. In particolare, viene ricordato che la ricerca è destinata principalmente a generare conoscenza, il che non sempre porta a una migliore cura per un dato paziente.

Questo errore è noto per facilitare quello che viene definito equivoco terapeutico e può causare fraintendimenti sul vero obiettivo che è quello di interventi sperimentali. In questo senso le linee guida invitano l'autore di uno studio ad avere maggiore consapevolezza non solo dei contenuti ma anche del tono.

\section{CONCLUSIONI}

Negli ultimi anni la ricerca sulle cellule staminali ha aperto possibili scenari di cura innovativi, poiché avere la possibilità di rigenerare un tessuto danneggiato dalla malattia è ben altra cosa rispetto al tentativo di arginare un danno. Di conseguenza, le cellule staminali hanno suscitato anche smisurate e infondate attese nella pubblica opinione, diventando uno scenario culturale, se non addirittura uno slogan, di futuribili vittorie sulla malattia.

Non va tuttavia dimenticato che la medicina potrà vincere alcuni o tanti limiti, ma riconsegnerà sempre l'uomo, anche se in modi nuovi, al suo limite fondamentale: egli non potrà non incontrare sofferenza, malattia e morte. Se si trascura questo aspetto, si rischia di caricare la ricerca sulle cellule staminali di una dimensione utopica che finirebbe per risultare frustrante e, in ultima istanza, disumanizzante.

La realtà attuale e futura delle cellule staminali richiede dunque una grande responsabilità d'azione; la ricerca e la divulgazione necessariamente devono essere coniugate con l'intelligenza etica che, insieme alla conoscenza medico-biologica e all'alleviamento delle sofferenze, miri al rispetto di tutto l'uomo e di ogni uomo.

Alla ricerca sulle cellule staminali e alle sue applicazioni terapeutiche dobbiamo chiedere di curare sempre meglio la salute, non di produrre la salvezza.

\section{BIBLIOGRAFIA}

1. Morgagni G, Radius JWM. De sedibus et causis morborum per anatomen indagatis: libri quinque (Vol. 4). Paris, France: Apud M.C. Compère; 1828.

2. Bichat X, Husson HM. Traité des membranes. Paris, France: Méquignon-Marvis; 1799.

3. Virchow R. Cellular-pathologie. Virchows Archiv 1855; 8:3-39.

4. Louis PCA. Recherches sur les effets de la saignée dans quelques maladies inflammatoires. Paris, France: Collection XIX; 1835.

5. Langer R, Vacanti JP, 1993. Tissue engineering. Science 260:920-6.

6. Dieckmann C, Renner R, Milkova L, Simon JC, 2010. Regenerative medicine in dermatology: biomaterials, tissue engineering, stem cells, gene transfer and beyond. Exper Dermatol 19:697-706.

7. Zhang X, Reagan MR, Kaplan DL. Electrospun silk biomaterial scaffolds for regenerative medicine. Adv Drug Deliv Rev 2009;61:988-1006.

8. Skalak R, Fox C. Preface. In: Tissue engineering. New York, NY. USA: AR Liss; 1988. 
9. Zhong SP, Zhang YZ, Lim CT. Tissue scaffolds for skin wound healing and dermal reconstruction. Nanomed Nanobiotechnol 2010;2:510-25.

10. Shin H, Jo S, Mikos AG. Biomimetic materials for tissue engineering. Biomaterials 2003;24:4353-64.

11. Langford CR, Cameron NR. Materials for tissue engineering and 3D cell culture. In: Bruns N., Kilbinger A.F.M. (eds.) Bio-inspired polymers. London, UK: Royal Society of Chemistry; 2016. pp. 460-89.

12. Becker AJ, McCulloch EA, Till JE. Cytological demonstration of the clonal nature of spleen colonies derived from transplanted mouse marrow cells. Nature 1963;197:452-4.

13. Friedenstein AJ, Chailakhjan RK, Lalykina KS. The development of fibroblast colonies in monolayer cultures of guinea-pig bone marrow and spleen cells. Cell Tissue Kinetics 1970;3:393-403.

14. Roobrouck VD, Ulloa-Montoya F, Verfaillie CM. Self-renewal and differentiation capacity of young and aged stem cells. Experim Cell Res 2008;314:1937-44.

15. Horwitz EM, Le Blanc K, Dominici M, et al. Clarification of the nomenclature for MSC: The International Society for Cellular Therapy position statement. Cytotherapy 2005;7:393-5.

16. Putera B, Wijaya, A, Yusuf I, Choon AT. Dynamic of circulating stem cells in ischemic stroke patient. Study of Hematopoietic Stem cells (HSCs), Mesenchymal Stem Cells (MSCs), Neural Stem Cells (NSCs), Endhotelial Progenitor Cells (EPCs), Very Small Embryonic (VSEL). Cytotherapy 2017;19:S202-4.

17. Gordeladze JO, Haugen HJ, Lyngstadaas SP, Reseland JE. Bone tissue engineering: state of the art, challenges, and prospects. In: A. Hasan (ed.) Tissue engineering for artificial organs: regenerative medicine, smart diagnostics and personalized medicine. Weinheim, Germany: Wiley-VCH Verlag GmbH \& Co. KGaA; 2017. pp. 525-51.

18. Alabdulkarim Y, Ghalimah B, Al-Otaibi M, et al. Recent advances in bone regeneration: The role of adipose tissue-derived stromal vascular fraction and mesenchymal stem cells. J Limb Length Reconstr 2017;3:4.

19. Roffi A, Krishnakumar GS, Gostynska N, et al. The role of three-dimensional scaffolds in treating long bone defects: evidence from preclinical and clinical literature-A systematic review. BioMed Res Int 2017; 2017:8074178.

20. Asghari F, Samiei M, Adibkia K, et al. Biodegradable and biocompatible polymers for tissue engineering application: a review. Artif Cells Nanomed Biotechnol 2017;45:185-92.

21. Geuna S, Nicolino S, Raimondo S, et al. Nerve regeneration along bioengineered scaffolds. Microsurgery 2007;27:429-38.

22. Nerem RM, Seliktar D. Vascular tissue engineering. Ann Rev Biomed Engin 2001;3:225-43.

23. Rouwkema J, Khademhosseini A. Vascularization and angiogenesis in tissue engineering: beyond creating static networks. Trends Biotechnol 2016;34:733-45.

24. Vigani B, Mastracci L, Grillo F, et al. Local biological effects of adipose stromal vascular fraction delivery systems after subcutaneous implantation in a murine model. J Bioact Compat Polym 2016;31:600-12.

25. Khademhosseini A, Langer R. A decade of progress in tissue engineering. Nature Prot 2016;11:1775-81.

26. Heath CA. Cells for tissue engineering. Trends Biotechnol 2000;18:17-9.
27. Griffith LG, Naughton G. Tissue engineering--current challenges and expanding opportunities. Science 2002;295: 1009-14.

28. Brunner D, Frank J, Appl H, et al. Serum-free cell culture: the serum-free media interactive online database. Altex 2010;27:53

29. Mannello F, Tonti GA. Concise review: no breakthroughs for human mesenchymal and embryonic stem cell culture: conditioned medium, feeder layer, or feeder-free; medium with fetal calf serum, human serum, or enriched plasma; serum-free, serum replacement nonconditioned medium, or ad hoc formula? All that glitters is not gold!. Stem Cells 2007;25:1603-9.

30. Rama P, Matuska S, Paganoni G, et al. Limbal stem-cell therapy and long-term corneal regeneration. New Engl J Med 2010;363:147-55.

31. Pauwelyn KA, Verfaillie CM. Transplantation of undifferentiated, bone marrow-derived stem cells. Current topics in developmental biology 2006;74:201-51.

32. Weissman IL. Translating stem and progenitor cell biology to the clinic: barriers and opportunities. Science 2000;287: 1442-6.

33. Ghadially R. 25 years of epidermal stem cell research. J Invest Dermatol 2011;132:797-810.

34. Weninger W, Wiedner M. The use of Keratinocytes: Things we should keep in mind! Eur Surg 2013;2013:1-7.

35. Mavilio F, Pellegrini G, Ferrari S, et al. Correction of junctional epidermolysis bullosa by transplantation of genetically modified epidermal stem cells. Nature Med 2006;12: 1397-402.

36. Gimble JM, Katz AJ, Bunnell BA. Adipose-derived stem cells for regenerative medicine. Circul Res 2007;100:1249-60.

37. Unger C, Skottman H, Blomberg P, et al. Good manufacturing practice and clinical-grade human embryonic stem cell lines. Human Mol Genet 2008;17:R48-53.

38. Sensebé L, Bourin P, Tarte K. Good manufacturing practices production of mesenchymal stem/stromal cells. Human Gene Ther 2010;22:19-26.

39. Regulation (EC) No 1394/2007 of the European Parliament and of the Council of 13 November 2007 on advanced therapy medicinal products and amending Directive 2001/83/ EC and Regulation (EC) No 726/2004 (Text with EEA relevance).

40. Bentzinger C, von Maltzahn J, Rudnicki MA. Extrinsic regulation of satellite cell specification. Stem Cell Res Ther 2010;1:27.

41. Brunelli S, Rovere-Querini P. The immune system and the repair of skeletal muscle. Pharmacol Res 2008;58:117-21.

42. Arnold L, Henry A, Poron F, et al. Inflammatory monocytes recruited after skeletal muscle injury switch into antiinflammatory macrophages to support myogenesis. J Experim Med 2007;204:1057-69.

43. Chazaud B, Sonnet C, Lafuste P, et al. Satellite cells attract monocytes and use macrophages as a support to escape apoptosis and enhance muscle growth. J Cell Biol 2003;163: 1133-43.

44. Parisi S, D'Andrea D, Lago CT, et al. Nodal-dependent Cripto signaling promotes cardiomyogenesis and redirects the neural fate of embryonic stem cells. J Cell Biol 2003; 163:303-14. 
45. Minchiotti G. Nodal-dependant Cripto signaling in ES cells: from stem cells to tumor biology. Oncogene 2005;24: 5668-75.

46. Guardiola O, Lafuste P, Brunelli S, et al. Cripto regulates skeletal muscle regeneration and modulates satellite cell determination by antagonizing myostatin. P Natl Acad Sci 2012;109:E3231-40.
47. Wagers AJ. The stem cell niche in regenerative medicine. Cell Stem Cell 2012;10:362-9.

48. Kamenova K, Caulfield T. Stem cell hype: media portrayal of therapy translation. Sci Transl Med 2015;7:278.

49. Bubela T, Li MD, Hafez M, et al. Is belief larger than fact: expectations, optimism and reality for translational stem cell research. BMC Med 2012;10:133. 